\title{
Business Scenarios for Incumbent Spectrum Users in Licensed Shared Access (LSA)
}

\author{
Petri Ahokangas ${ }^{1}$, Marja Matinmikko ${ }^{2}$, Seppo Yrjölä ${ }^{3}$, Miia Mustonen $^{2}$, Esko Luttinen ${ }^{4}$, Anri Kivimäki $^{1}$, \\ and Jukka Kemppainen ${ }^{5}$
}

\begin{abstract}
This paper presents business scenarios for incumbent spectrum users in the new Licensed Shared Access (LSA) concept. The LSA concept aims at improving spectrum usage efficiency by introducing additional licensed spectrum users on spectrum bands whose incumbent use would permit it, while guaranteeing certain quality of service $(Q 0 S)$ for all users. The LSA concept could help mobile network operators (MNOs) to gain access to new spectrum bands on a shared basis in a timely manner. As the LSA concept is based on voluntariness, it needs to provide incentives for the incumbent spectrum users for the introduction of sharing. Using a foresight approach called integral scenario methodology, we propose a set of scenarios for incumbent spectrum users in LSA based on their business focus (defensive vs. aggressive) and mode of change (open vs. closed). The created scenarios are described and analyzed from regulation, business and technology perspectives, highlighting the business potential created by the introduction of LSA. The evaluation of the developed business scenarios indicates that a defensive approach for the business focus for incumbents might be preferred to focus narrowly on traditional business models. However, an aggressive approach to pursue new business opportunities with LSA might open up new opportunities which, today, cannot yet be foreseen.
\end{abstract}

Keywords- Business Scenarios, Licensed Shared Access, LSA, Spectrum sharing

\section{INTRODUCTION}

“...we must make available even more spectrum and create new avenues for wireless innovation. One means of doing so is by allowing and encouraging shared access to spectrum that is currently allocated exclusively for Federal use. Where technically and economically feasible, sharing can and should be used to enhance efficiency among all users and expedite commercial access to additional spectrum bands, subject to adequate interference protection for Federal users, ...we should also seek to eliminate restrictions on commercial carriers' ability to negotiate sharing arrangements with agencies. To further these efforts, while still safeguarding protected incumbent systems that are vital to Federal interests and economic growth, this memorandum directs agencies and offices to take a number of additional actions to accelerate shared access to spectrum. [1]"

Mobile broadband is growing at a rapid pace [2], placing increasing demands on the already scarce spectrum resources especially in urban areas. This spectrum scarcity puts the

\footnotetext{
${ }^{1}$ Oulu Business School, Oulu, Finland. Petri.Ahokangas@oulu.fi, Anri.Kivimaki@oulu.fi

${ }^{2}$ VTT Technical Research Centre of Finland, Oulu, Finland.

Marja.Matinmikko@vtt.fi, Miia.Mustonen@vtt.fi

${ }^{3}$ Canno Vriölä Nolis Solutione and Natwonrle nulı, Finland.
}

mobile network operators (MNOs) providing mobile broadband services to a new situation and against a disruptive change. Regulators all over the world, such as the above quote from President Barack Obama, are considering spectrum sharing in the future due to difficulties in finding unused exclusive spectrum. Spectrum sharing where two or more systems operate in the same spectrum band is receiving growing importance to meet the growing demand while maintaining the rights of incumbent systems operating in the bands. This development highlights the role of the incumbent spectrum holders and opens up new business opportunities as well as risks for the incumbents due to increasing pressure for spectrum sharing.

Spectrum sharing considerations have evolved from license-exempt approach with uncontrolled interference environment towards more controlled setups which could offer better operational conditions for the involved systems. To this end, the new Licensed Shared Access (LSA) concept has emerged in European regulation for introducing additional licensed users on bands with existing incumbent licensed users while providing certain quality of service (QoS) for both [3]. The application of the LSA concept into mobile broadband is receiving growing interest to make new bands available for MNOs in a timely manner on a shared basis with incumbents. Special emphasis in regulation and standardization in Europe is currently put on the LSA concept in the $2.3-2.4 \mathrm{GHz}$ band that has high commercial potential as assessed in [4].

In the development of new spectrum sharing concepts, the consideration of the business aspects is of utmost importance to create a sharing framework that benefits all involved stakeholders. Previous works on the business aspects of spectrum sharing have mainly focused on the role of the MNO in spectrum sharing. For example, the emergence of new MNO roles in shared spectrum bands were discussed in [5]. A technoeconomic analysis for MNOs for selecting different types of spectrum bands in indoor scenarios was presented in [6]. Simple rules for MNOs in general in spectrum sharing were developed in [7] highlighting the different business considerations for big dominating and small challenger MNOs.

An important part of the business considerations is the development of business scenarios. The authors in [8] developed scenarios for secondary spectrum access where secondary users opportunistically access underused spectrum bands. General level business scenarios for spectrum sharing for mobile broadband were developed in [9] where the authors outlined business scenarios for the mobile broadband with 
spectrum sharing and initial business models without focusing on specific sharing concepts. Business aspects of the generic concept of private commons were studied in [10] where opportunistic secondary access was allowed for a fee. Spectrum sharing is all about rights associated with the radio spectrum among the involved stakeholders which are discussed in [11]. The authors in [11] identify the broad context where spectrum sharing is not only about spectrum rights but involves other rights, such as rights to access land and rights to operate specific services.

Previous work on sharing with the new LSA concept which differs from opportunistic secondary access due to its licensed nature has focused on the role of the MNO in sharing [12]. There is no prior work on the business aspects, opportunities, or alternatives of the incumbent spectrum users in the LSA concept. This paper focuses on the LSA concept in Europe in the 2.3-2.4 GHz band. By focusing on incumbents' role in LSA, this paper seeks to discuss the following research questions in the time frame of next five years:

1. What kind of change factors influence Incumbents' future Business Scenarios?

2. What kind of Business Scenarios could be created for incumbents based on the identified change factors?

As this research is about the future, we apply a foresight approach called integral scenarios methodology to create the scenarios. This paper is organized as follows. The LSA concept is introduced in Section II. The methodology for scenario building is presented in Section III. The developed business scenarios for incumbent spectrum uses in LSA are shown in Section IV. Finally, conclusions are drawn in Section V.

\section{LICENSED SHARED ACCESS (LSA) CONCEPT}

Licensed Shared Access (LSA) is a regulatory approach that aims at facilitating more efficient use of the radio spectrum. LSA could be used to introduce additional licensed users to spectrum bands that currently encompass other incumbent use while protecting incumbents' rights while providing QoS guarantees also for the licensee.

The Radio Spectrum Policy Group (RSPG) of the European Commission (EC) has defined LSA as "A regulatory approach aiming to facilitate the introduction of radiocommunication systems operated by a limited number of licensees under an individual licensing regime in a frequency band already assigned or expected to be assigned to one or more incumbent users. Under the Licensed Shared Access (LSA) approach, the additional users are authorised to use the spectrum (or part of the spectrum) in accordance with sharing rules included in their rights of use of spectrum, thereby allowing all the authorized users, including incumbents, to provide a certain Quality of Service (QoS)" [3].

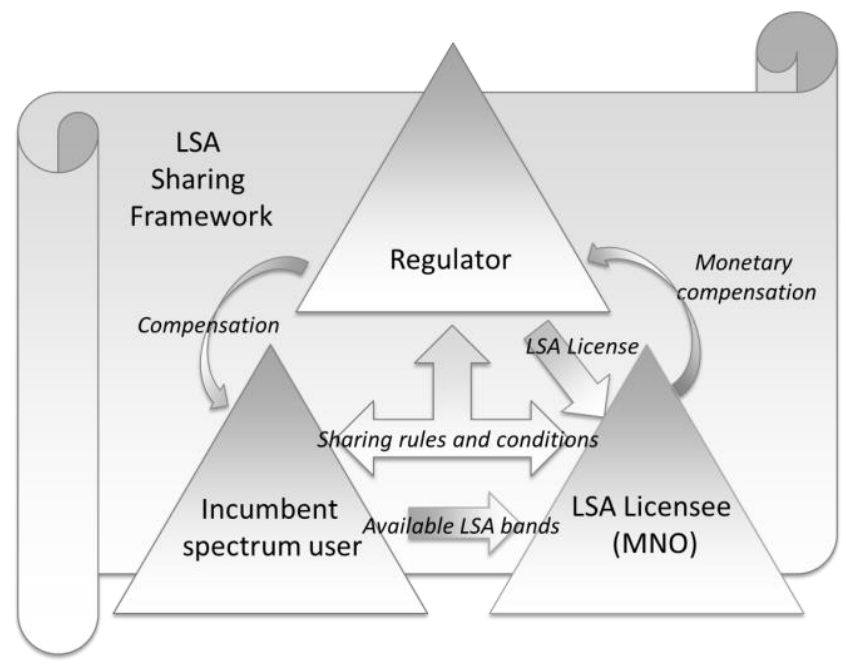

Figure 1. LSA stakeholders and sharing framework.

The key stakeholders in LSA include regulator, incumbent spectrum user (incumbent) and LSA licensee. They define and agree the rules and conditions for sharing under the LSA sharing framework which is described in [13]. Figure 1 illustrates the key stakeholders in the LSA concept. The regulator, incumbent and LSA licensee (MNO) develop and agree on the sharing rules and conditions. The incumbent informs available LSA bands for the MNO according to an LSA license issued by the regulator to the MNO. The MNO will pay for the license to the regulator and the regulator may compensate the incumbent for sharing. The LSA concept is based on voluntariness and thus it needs to offer benefits to all involved stakeholders.

The LSA concept is currently under study in European regulation [13] and standardization [14] with a special focus on the 2.3-2.4 GHz band. This band is currently used for different purposes in Europe as summarized in [15]. For example, in Finland the band is used for amateur services and wireless cameras and video links, in Germany for telemetry, cordless cameras and amateur service, in France for civilian video link and governmental aeronautical telemetry, in UK for military and emergency services, and in Greece for public safety networks. Thus, there are different types of incumbent spectrum users even in the same band in Europe depending on the national situation. Here, we consider both nongovernmental (e.g. wireless cameras and video links) and governmental (e.g. public safety, military) incumbents.

\section{RESEARCH METHODOLOGY FOR SCENARIO BUILDING}

This section summarizes the research methodology and data used in the study for building business scenarios.

\section{A. Integral scenarios methodology}

Planning of integral scenarios is a foresight technique used for strategic analysis and business planning. The basic idea of the integral scenario approach is that scenarios consider multiple alternative futures [16] [17] and they are focused around a business case with a specific purpose. This research approach builds around an interactive, collaborative process that relies strongly on conversation among a variety of participants, from multiple perspectives, concerned with the 
research project. Conversation allows meaning from a range of different worldviews to be shared and negotiated for studying, theorizing and otherwise engaging the future for helping to create it [18].

The scenarios presented in this paper were created in a series of future-oriented workshops organized by the Finnish CORE+ research project in January 2014. The scenarios were created with a five-year future perspective as of beginning of 2014. The research process comprised 1) identifying the critical change factors, 2) assessing their impact and possible consequences on incumbents, 3) building and selecting the scenario axes, 4) creating the business scenarios, and 5) evaluating them. Foresight, by definition, is future focused and its reliability and validity are cannot be controlled. Instead, the qualitative focus of research is in how probable, plausible, and preferable the outcomes appear. Also, the collaborative and conversation based method how the futures were created was regarded as way to ensure the quality of the research. [19]

\section{B. Change factors influencing incumbents' business scenarios as data}

As a starting point for identifying the critical change factors for the scenarios, the workshop participants reviewed a multitude of research and commercial sources for change factors around cognitive radio, telecommunications (infrastructure, devices/equipment, services), cloud computing, internet-of-things, ICT consumer business, digital media, security, as well as defense/military/homeland and security/public safety [20] [21] [22] contexts. The relevance of the change factors within the LSA context was assessed against their potential magnitude of impact (great/small) and predictability of consequences (high/low), and those estimated simultaneously as having great impact and low predictability were identified as critical change factors. The critical change factors were analyzed from the perspective of the whole LSA concept, including several types of Incumbents and other stakeholders reviewed in the aforementioned contexts. This was done in order to avoid the risk of prematurely focusing on the most evident LSA business cases only. Table I below summarizes the identified critical change factors.

TABLE I. CRITICAL ChANGE FACTORS FOR INCUMBENTS

\begin{tabular}{|c|c|c|c|}
\hline $\begin{array}{c}\text { Change } \\
\text { Factor }\end{array}$ & \multicolumn{3}{|c|}{ Change factor may lead Incumbent to... } \\
\hline $\begin{array}{c}\text { Cost } \\
\text { pressure }\end{array}$ & $\begin{array}{c}\text { seek for internal } \\
\text { efficiency }\end{array}$ & $\begin{array}{c}\text { seek for infra } \\
\text { sharing }\end{array}$ & $\begin{array}{c}\text { seek for } \\
\text { alternative } \\
\text { commercial } \\
\text { technologies }\end{array}$ \\
\hline $\begin{array}{c}\text { Media } \\
\text { disruption }\end{array}$ & $\begin{array}{c}\text { change } \\
\text { terrestrial TV to } \\
\text { IPTV }\end{array}$ & $\begin{array}{c}\text { turn PMSE } \\
\text { streams to use } \\
\text { LTE }\end{array}$ & $\begin{array}{c}\text { convergence of } \\
\text { businesses and } \\
\text { technologies }\end{array}$ \\
\hline $\begin{array}{c}\text { Need for } \\
\text { security }\end{array}$ & $\begin{array}{c}\text { emphasize cyber } \\
\text { security }\end{array}$ & $\begin{array}{c}\text { emphasize } \\
\text { securing critical } \\
\text { infra }\end{array}$ & $\begin{array}{c}\text { emphasize } \\
\text { secure user } \\
\text { identification }\end{array}$ \\
\hline $\begin{array}{c}\text { Increased } \\
\text { collaboration }\end{array}$ & $\begin{array}{c}\text { collaborate with } \\
\text { regulator }\end{array}$ & $\begin{array}{c}\text { collaborate with } \\
\text { MNOs }\end{array}$ & $\begin{array}{c}\text { turn to look for } \\
\text { new business } \\
\text { opportunities }\end{array}$ \\
\hline $\begin{array}{c}\text { Changing } \\
\text { licensing } \\
\text { modes }\end{array}$ & $\begin{array}{c}\text { turn more short- } \\
\text { term or semi- } \\
\text { static }\end{array}$ & $\begin{array}{c}\text { turn more } \\
\text { geographically } \\
\text { constrained }\end{array}$ & $\begin{array}{c}\text { adapt to shared } \\
\text { spectrum }\end{array}$ \\
\hline
\end{tabular}

As unpredictable, the critical change factors presented in Table I can be considered to exhibit a variety of contradictory or otherwise different outcomes for the incumbents. The items presented are therefore not ranked according to their importance or magnitude of impact. We see that incumbents themselves are not the ones necessarily needing new spectrum, but the cost pressures faced by companies and government owned entities in the current economic downturn in general increase the need for efficiency and induces sharing in many forms and incumbents may seek internal efficiency, seek to share infrastructure, or seek to utilize alternative commercial technologies. On one hand media disruption may influence incumbents to favor IPTV over terrestrial TV, turn program making and special events (PMSE) streams to use LTE technology and generally result in convergence of technologies and businesses. Also, media disruption may open up opportunities and demonstrate new ways of operating for incumbents regardless of the sector or type of service they represent. On the other hand, incumbents' security needs are increased along with those of the service users and public services. E.g., one critical example of this may be the need to share information concerning the use of the spectrum between the incumbents and the other users: from whom and to what degree the information is shared may give rise to different security concerns. Collaboration may take different forms as incumbents may favor regulator or alternatively MNOs as partner or look for completely new business opportunities where new kind partnerships may arise with new partners. This, of course, depends on the incumbents overall inclination toward doing business. Within LSA there may also emerge pressures to turn toward more short-term or semi-static licensing or utilize geographically constrained licenses. On the opportunistic side, incumbents may also actively adapt to sharing rather than be "regulated" to sharing.

The examination of the change factors was conducted so as to identify dimensions that might be shared by the outcomes or that might connect the different alternative outcomes. The identified change factors and their alternative outcome categories were assessed, and two business scenario dimensions were identified: business focus and mode of change.

\section{FOUR INCUMBENT SCENARIOS IN LSA}

In our scenario work for LSA, the baseline assumption is that the overall efficiency of spectrum use is improved by means of spectrum sharing. As the LSA concept is based on voluntariness of the stakeholders, the regulator is not foreseen to force incumbents to accept sharing. Instead, successful deployment of LSA concept requires that incumbents see benefits from sharing. As a step towards identifying benefits, this paper develops business scenarios for the incumbents next.

For creating the business scenarios for incumbent spectrum users in the LSA concept, two orthogonal (not related to each other) dimensions were created and selected for the axes: business focus (x-axis) and mode of change (y-axis). The business focus was divided into defensive and aggressive, where the aggressive business focus was to generate new revenue from new business opportunities (external thing emphasized) whereas the defensive business focus was to 
increase cost efficiency within existing businesses (internal things emphasized). These two extremes of the continuum can be regarded to reflect strongly the choices regarding the value creation and capture logics and strategies of the incumbents. The mode of change was divided into interactive open mode and control-oriented closed mode, where the open mode highlighted the convergence of businesses and technologies and the closed mode to secure critical infrastructure. The open mode of change was identified to reflect more business-toconsumer type of developments and the closed mode the business-to-government and business-to-business type of developments.

The workshop participants labeled the scenarios after Winnie-the-Pooh characters. In the creation of the scenarios the workgroup used the three dimensions presented in [7]: regulation, business, and technology. Regulation shapes the business environment by defining the rules. Business decisions are taken based on the regulatory environment and technology is developed according to the business decisions.

\section{A. Eeyore scenario}

The Eeyore scenario is characterized with high cost pressure and high media disruption with high convergence of business technology. The role of the content and users in all communications is emphasized. At the same time, different communications technologies are converging, leaving the incumbents with pressures to scale up their activities due to increased competition and decreased margins. In this scenario the incumbents want to hold on to their existing business model and reactively adapt to the changing business environment.

\section{1) Regulation}

In this scenario, the regulator actively promotes spectrum sharing. The regulator aims at improving the efficiency of the spectrum use to make most of it. Additionally, the regulator may put pressure on the incumbents to pay for the actual use of spectrum. In high cost pressure, this may lead the incumbents to facilitate spectrum sharing to avoid losing the bands completely.

\section{Convergence of business and technologies}

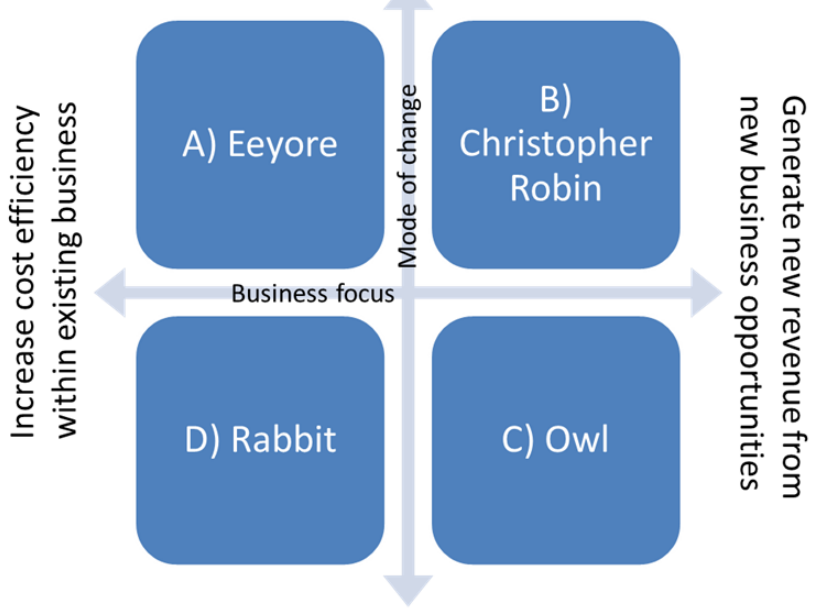

Secure critical infrastructure

Figure 2. Four Incumbent Scenarios
2) Business

From the business point of view, in this scenario the incumbents fear competition from new players that might arise from opening up bands for sharing. Regardless of the fear of competition and high cost pressure, the incumbents want to continue with their existing business models. On the other hand, high media disruption is likely to lead to increasing service demand, as in the example of PMSE services. This results in increased spectrum demand leaving less spectrum for sharing. The role of sharing among incumbents may be emphasized over sharing to MNOs if the amount of spectrum for sharing is low.

\section{3) Technology}

Due to high cost pressure, incumbents want to exploit existing equipment base to as high degree as possible. With the growing demand for incumbent service, such as PMSE, the need to develop coordination mechanisms arises within the incumbent service.

\section{B. Christopher Robin scenario}

In the Christopher Robin scenario, the incumbent is eager to grasp new business opportunities to generate new revenue. Convergence of business and technology is high and the incumbent sees it as an opportunity and actively develops new business models. During the recent years, convergence has had a remarkable influence on the ways how MNOs do business by introducing new services such as cable TV on top of traditional cellular connectivity. This is an opportunity for incumbents to scale up their business to MNO role.

\section{1) Regulation}

In this scenario, the regulator actively promotes sharing and opens up shared spectrum for new purposes. The regulator actively helps the incumbents to open up new opportunities increasing the value of spectrum. Regulator could relax licensing conditions to allow incumbents to offer additional services in their current bands.

\section{2) Business}

Incumbents could be interested to take up a new role by starting to offer e.g. mobile services. The incumbents actively search for new business models by e.g. bundling of service offerings.

3) Technology

From the technology perspective, spectrum sharing expands to sharing also the infrastructure to create new business opportunities. Unified technology platforms that are capable of offering versatile services are taken into use and the use of new technology (e.g., carrier aggregation and supplementary downlink) is promoted. LSA tools are widely used for sharing.

\section{Owl scenario}

The Owl scenario is characterized by the incumbents' role in critical infrastructures within public or governmental services rather than entertainment or social media. In this scenario new business opportunities are actively pursued with the focus on securing critical infrastructure. Also in this scenario, sharing is a normal part of everyday activity and mechanisms for sharing are commonly used. Capacity demands of different critical services are balanced with sharing. 


\section{1) Regulation}

The regulator actively promotes sharing and adds flexibility to incumbents' spectrum use based on demand. For example, sharing in normal situation allows the incumbent to get extra capacity when needed. Incumbents' compensations for the spectrum may become based on their actual spectrum usage. Incumbents' operations are ensured in all cases of emergency

2) Business

From the business point of view in public/governmental services, the value of spectrum is a political decision. Sharing based on LSA is an opportunity for incumbents to show their cooperative attitude and societal responsibility by improving the efficiency of spectrum use. In addition to utilize and to make profit, incumbents could offer new secure critical services for new kind of partners, for example within healthcare or energy sector, provided that regulatory schemes allow it.

\section{3) Technology}

In this scenario, unified technology platforms and off-the-shelf technologies, such as LTE, are commonly used and infrastructure is shared. Flexibility and scalability become important.

\section{Rabbit scenario}

In the Rabbit scenario the incumbents experience high cost pressure while ensuring that critical infrastructures are secured. Therefore, the incumbents rather look for internal efficiency than new opportunities. They exploit their existing infrastructure and equipment as much as possible to fulfil their societal targets without jeopardizing security and reliability.

\section{1) Regulation}

In this scenario, there is a political pressure to monetize spectrum assets leading to enforcement of sharing. The regulator actively promotes sharing and defines the value of spectrum to be shared with the aim to improve the efficiency of spectrum use. Revenues are generated by the government from sharing governmental spectrum while ensuring operations in emergencies.

\section{2) Business}

Instead of aiming at generating new business from new services, this scenario ensures efficient use of current assets. By allowing sharing, incumbents could continue their operations in the bands to fulfil their obligations defined by the society with minimum additional investment.

3) Technology

Due to cost pressures, incumbents want to exploit their existing equipment base to the maximum to cut costs. Allowing sharing in governmental bands would allow incumbents to continue using the same equipment in the same band without pressure for re-farming. In case of new investments, off-the-shelf technologies are preferred to save in costs. On the other hand, incumbents want to ensure their current operations without new investments in sharing technology.
TABLE II. EVALUATION OF SCENARIOS

\begin{tabular}{|c|c|c|c|c|}
\hline \multirow{2}{*}{ Criteria } & \multicolumn{4}{|c|}{ Alternative business scenarios } \\
\cline { 2 - 5 } & A) Eeyore & $\begin{array}{c}\text { B) Christopher } \\
\text { Robin }\end{array}$ & C) Owl & D) Rabbit \\
\hline Probability & 1 & 3 & 4 & 2 \\
\hline Plausibility & 1 & 4 & 3 & 2 \\
\hline Preferability & 2 & 4 & 3 & 1 \\
\hline
\end{tabular}

\section{E. Evaluation of the scenarios}

The scenario logic includes the evaluation of the quality of the scenarios as the last step. The created first two scenarios (Eeyore and Christopher Robin) focus on providing services to consumers while the last two (Owl and Rabbit) provide services within the governmental regime. Thus, the relevance of the developed scenarios depends on the actual incumbent usage in the country considered.

The evaluation of the four business scenarios was based on three dimensions, their probability, plausibility, and preferability from the incumbent perspective [23]. The assessment of the probability was based on the identified trends the change factors depicted or represented regarding the alternative futures. The assessment of plausibility was based on the events that were used to describe or characterize the alternative futures. And finally, the assessment of preferability was based on the choices the incumbents were anticipated to face in the four alternative futures. The method used in the assessment was ranking with a scale from 1 (highest) to 4 (lowest) and with a rule to avoid even rankings across the alternative business scenarios. The results of the assessment are presented in Table II.

Regarding their probability within the next five years, based on the identified trends, we see that the two scenarios where the incumbents' focus is more on seeking cost efficiency are more probable than scenarios focusing on generating new revenues from new business opportunities. While the Eeyore scenario appears as the most probable, the Rabbit scenario is almost as likely. The probability of Christopher Robin and Owl scenarios depends on the regulatory developments for creating attractive opportunities for incumbents as well as on the inexperience of incumbents in diversifying to new businesses. Based on anticipated events, the plausibility of the scenarios appeared almost identical with the probability evaluations, the only difference being that the Owl scenario was regarded more plausible than the Christopher Robin scenario. This was because of the growing importance of securing critical infrastructure. The most preferable of the scenarios was the Rabbit scenario, based on its' opportunity to generate new revenues by the incumbents. The second most preferable of the scenarios by the incumbents was the Eeyore scenario as it was nevertheless considered as the most easy for the incumbents.

As a whole our evaluation suggests that the Eeyore and Rabbit scenarios might be suitable choices for incumbents utilizing LSA regarding the way how to develop their business in the future. 


\section{DISCUSSION AND CONCLUSIONS}

In this paper, business scenarios were created for the new Licensed Shared Access (LSA) concept enabling mobile broadband to use spectrum on a shared basis with incumbent spectrum users. In particular, the role of the incumbents in the LSA concept was addressed and the set of business scenarios were developed from incumbent perspective to motivate the introduction of LSA. By using integral scenario methodology, critical change factors were identified to create the dimensions for scenarios. The developed incumbent business scenarios addressed business focus (defensive vs. aggressive) and mode of change (open vs. closed). The business focus was seen to comprise either an aggressive approach where the aim was to generate new revenue from new business opportunities, or a defensive approach where the aim was to increase cost efficiency within existing businesses. The mode of change considered either an interactive open mode which referred to high media disruption, or a control-oriented closed mode refering to governmental incumbent activity. The scenarios were described considering regulation, business and technology perspectives. Finally, the developed scenarios were evaluated with respect to their probability, plausibility and preferability.

The evaluation of the developed scenarios indicated that the defensive approaches for the business focus might be preferred for the incumbents to focus narrowly on traditional business models with the idea to scale up to avoid the pressures to share the spectrum with other players. However, the aggressive approach might offer new opportunities which, today, cannot be even foreseen. To conclude, the analysis supports the argument that regulation around LSA strongly influences incumbents' ideas of what kind of business opportunities and business environment they will face in the future. As a consequence, the technological development is affected from both regulation and business perspective, and that the era of technology-push can be regarded as ended. Also, the analysis indicates that the business domain has a growing impact on the regulatory schemes for LSA.

\section{ACKNOWLEDGMENT}

This work has been performed in the CORE+ project. The authors would like to acknowledge the project consortium: VTT Technical Research Centre of Finland, University of Oulu, Centria University of Applied Sciences, Nokia Solutions and Networks, PehuTec, EXFO, Elektrobit, Anite, Rugged Tooling, Finnish Defence Forces, Finnish Communications Regulatory Authority, and Tekes - the Finnish Funding Agency for Innovation.

\section{REFERENCES}

[1] Presidential Memorandum, "Expanding America's Leadership in Wireless Innovation," The White House, June 2013.
[2] Report ITU-R M.2243. Assessment of the global mobile broadband deployments and forecasts for International Mobile Telecommunications. 2011.

[3] European Commission Radio Spectrum Policy Group RSPG13-538 Opinion on Licensed Shared Access, Brussels. November 2013.

[4] T. Lavander, P. Marks, and S. Wongsaroj, The economic benefits of LSA in $2.3 \mathrm{GHz}$ in Europe. Plum Consulting. December 2013.

[5] D. H. Kang, K. W. Sung and J. Zander, High capacity indoor and hotspot wireless systems in shared spectrum: a techno-economic analysis, IEEE Commun. Magazine, vol. 51, no. 12, pp. 102-109.

[6] C. Dahlberg, L. Zhicheng, A. Pradini and W. K. Sung, A technoeconomic framework of spectrum combining for indoor capacity provisioning, in Proc. IEEE PIMRC 2013, pp. 2759-2763.

[7] P. Ahokangas, M. Matinmikko, S. Yrjölä, H. Okkonen and T. Casey. "'Simple rules" for mobile network operators' strategic choices in future spectrum sharing networks," IEEE Wireless Commun., vol. 20, no. 2, pp. 20-26, 2013.

[8] Y. Hwang, S.-L. Kim, Ki Won Sung and J. Zander. "Scenario making for assessment of secondary spectrum access," IEEE Wireless Commun., vol. 19, no. 4, pp. 25-31.

[9] P. Ahokangas, M. Matinmikko, J. Myllykoski, and H. Okkonen "Future scenarios, ecosystems and business models for cognitive radio systems," VTT Technology 55. 2012. $54 \mathrm{p}$.

[10] A. Al Daoud, M. Alanyali, and D. Starobinski, "Economic viability of private commons: Framework and guidelines for profitability," Telecommunications Policy, vol. 37, no. 2-3, pp. 231-240.

[11] L. Cui, M. M. Gomez and M. B. H. Weiss, Dimensions of cooperative spectrum sharing: Rights and enforcement," in Proc. IEEE DySPAN 2014.

[12] P. Ahokangas, M. Matinmikko, S. Yrjölä, M. Mustonen, H. Posti, E. Luttinen, and A. Kivimäki, "Business models for mobile network operators in Licensed Shared Access (LSA)," in Proc. IEEE DySPAN 2014.

[13] ECC Report 205. Licensed Shared Access. Feb. 2014

[14] ETSI, "Mobile Broadband services in the 2300-2400 MHz frequency band under Licensed Shared Access regime", ETSI TR 103.113 v 1.1.1, July 2013.

[15] ECC document FM(12)017rev1, "Results of the WG FM questionnaire to CEPT administrations on the current and future usage of frequency band 2300-2400 MHz," April 2012.

[16] K. Van Den Hejden, "Scenarios - The art of strategic conversation," John Wiley \& Sons., 2007: England. 2nd ed.

[17] C. Stewart, "Integral scenarios: Reframing theory, building from practice", Futures, vol 40, 2008, 160-172.

[18] J. Voros, "Integral Futures: An approach to futures inquiry", Futures 40, 2007, 190-201.

[19] J. Floyd, "Action research and integral futures studies: A path to embodied foresight", Foresight, vol. 44, 2012, 870-882.

[20] V. Ollikainen (ed.) New Electronic Media (NELME): 2016 Foresight. VTT Technology 31. 2012.62 p.

[21] D. Lewin, P. Marks and S. Nicoletti, Valuing the use of spectrum in the EU. Plum Consulting. April 2013. 73 p.

[22] Ericsson. 10 Hot consumer trends 2014. 12 p.

[23] P. Reason and H. Bradbury (edss), The SAGE Handbook of Action Research. Participative Inquiry and Practice. 2nd Ed. Sage Publications, 2008 